\title{
Parlaying Value
}

\section{Capital in and Beyond Virtual Worlds}

Thomas Malaby

University of Wisconsin-Milwaukee

Recent scholarship has made it clear that people within synthetic worlds (otherwise known as virtual worlds or MMORPGs) produce commodities and currencies with market value, whereas other work has established the increasing importance of social networks within and between worlds and across the boundary that appears to separate them from the rest of users' lives. To tie these two threads together and account for the use of these environments for the development of expertise and credentials, the author proposes adding a third form, cultural capital, to the mix and outlines a model for understanding capital in all its manifestations: material, social, and cultural. This model will make it possible to explore how actors within synthetic worlds transform, or parlay, these forms from one into the other and how these forms are used across all the domains wherein users act, blurring any qualitative distinction between virtual and real worlds.

Keywords: $\quad$ social capital; cultural capital; virtual worlds; MMORPGs

\section{Card Carrying Culture}

In February of 2005 an individual by the name of Kermitt Quirk signed a contract licensing the use of a very popular game that he had made, called Tringo, to a company interested in distributing the game worldwide. He designed, scripted, built, and

Author's Note: The research on which this article is based was conducted with the vital support of the National Science Foundation, through its subprogram on Ethics and Values Studies in the Science \& Society Program (Grant \# 0423043), and by a fellowship from the Center for 21st Century Studies at the University of Wisconsin-Milwaukee. I am indebted to the many colleagues and friends for their willingness to comment on this work in its prepublication form, including Kalman Applbaum, Ingrid Jordt, Edward Castronova, Dan Hunter, F. Gregory Lastowka, Ren Reynolds, and Jeff Rutenbeck. James Paul Gee, Kurt Squire, Constance Steinkuehler, and the graduate students of the Games, Learning, and Society Program at the University of Wisconsin-Madison were incredibly welcoming and gave important feedback during a presentation of some of these ideas. In addition I would like to highlight the Ludium I, a conference at The Arden Institute, a Center for the Study of Synthetic Worlds at Indiana University, and State of Play III: Social Revolutions (in particular the Digital Identity workshop, chaired by Ren Reynolds and Susan Crawford), as particularly stimulating venues for my development of these ideas. Of course, all shortcomings of the preceding are mine alone. Finally, I want to express my appreciation to Linden Lab, for being willing to let an anthropologist cross into their domain of synthesis and world creation. Address correspondence to Thomas M. Malaby, PhD, Department of Anthropology, University of Wisconsin-Milwaukee, P.O. Box 413, Milwaukee, WI 53201; e-mail: malaby@uwm.edu. 
Figure 1

The Tringo Trading Card (Front and Back)



initially distributed the game in Second Life, an online synthetic world (these are often called virtual worlds, but see the following) where residents have access to the tools to create their own content, including 3-D modeling, scripting (programming), and texture mapping, and where they furthermore own the intellectual property rights to whatever they create. Tringo had already become all the rage in Second Life in late 2004, with residents flocking to Tringo locations to play and socialize, and Quirk turned this popularity into a significant monetary gain.

A remarkable cultural artifact speaks to this phenomenon: a trading card. The cards, a product of Linden Lab's marketing team, are distributed at a variety of events where Linden Lab has a presence, including academic conferences, trade shows, and the like. Linden Lab aspires to leverage the power of trading cards-which ideally travel through social networks - to generate interest in Second Life and ultimately more users. Kermitt Quirk's Tringo is the first card in the Games series and features a screenshot of a game of Tringo (taken within Second Life) on its front, along with the Second Life logo (see Figure 1). On the back is the following information (the first paragraph is highlighted in a box; I have preserved as much of the original formatting as possible here): 


\title{
GAMES SERIES 1
}

\section{Tringo}

\author{
What is Tringo? \\ A simple multiplayer game with elements of Bingo and a fast-action jigsaw \\ arcade game, Tringo consists of a display board, to track scores and pieces \\ in play, and game cards, for the individual players. After players place their \\ bets in a winner-take-all pot, they compete with each other to fit their pieces \\ together onto their cards.
}

Creator: Kermit [sic] Quirk

Second Life Resident since: 9/4/2004

First Life Occupation: Systems Analyst/Programmer

Second Life Occupation: Game Developer

Business: Tringo and Krytterz (COMing July '05)

store [sic] Location: KermitT's Korner, Jarawara $(141,123)$

Estimated in-world net worth: L\$1.6 MILLION (CURRENT US\$ MARKET VALUE:

\$64000)

\section{Business Milestone:}

Selling Tringo's non-Second Life rights to Donnerwood Media for five figures. (Wall Street Journal, March 3, 2005) "I always intended to sell Tringo, but Inever expected it would sell so well. The whole thing kinda snuck up on me."

\section{Transforming Tringo into a Business:}

At the beginning I held a few Beta test events and that started getting people interested. Sales so far have simply been by word of mouth, all sold from a single vendor on my land. Eventually I'll spread out a few more vendors and I have plans for a bit of advertising too.

This is a dense cultural document filled with carefully written texts that aspire to teach the reader about many things. I will return to an extended discussion of the card at the conclusion of this article, but it is enough to note for the moment that it seeks to connect things of value (e.g., income/net worth, connections, occupation) across two different domains of human action: Second Life and "First Life" (a resident's existence beyond Second Life, in most cases taken to mean "real life," outside of online worlds altogether). Also, as a trading card, this object constitutes in itself an artifact that aspires to be valued, and this value furthermore depends on its potential for circulation in social networks or material reward through auction.

We can read this object, and others like it, as cultural artifacts that aspire (here, from the point of view of Linden Lab's marketing team) to teach us about Second 
Life, and as such they reveal an economy in a broader sense-how status, expertise, and the market are all interrelated in Second Life. What is more, they point to how these things of value circulate not just within a particular environment or domain like Second Life but also beyond it, to other arenas of human experience. In what follows, I weave together existing threads of thought about value and practice in these worlds and beyond them to articulate more precisely a framework until now only casually applied, one that should enable us to make sense not only of objects like this trading card but indeed of the social practices it documents, the parlaying of value within and across the wide domains of human action, including synthetic worlds.

\section{Capital Ideas}

Some of the largest and most viable online communities to date are the persistent, open-ended, graphically intensive, and three-dimensional online environments known variously as MMOGs (massively multiplayer online games), MMORPGs (massively multiplayer online role-playing games), and virtual worlds. The accepted term for these environments is still very much in flux, with virtual worlds currently enjoying some precedence. Calling these environments worlds has its advantages, as the word best captures the open-ended and broad nature of these arenas, pointing to the ever-increasing possibilities for action within them. When referring to them as a distinct set, I choose to follow Castronova (2005) and use the term synthetic worlds for two reasons. First, this highlights how these worlds are the product of human action - that is, they are built. Second, the term virtual, although having the advantage (through its associated uses, i.e., virtual reality) of quickly conveying an image of what these worlds entail in the popular imagination, nonetheless founders on the very distinction that animates it: the real and the virtual. It is partly with an aim toward jettisoning the qualitative break implied by this pair of terms that I opt for synthetic worlds when referring to them as a group.

More broadly however, this article seeks to demonstrate that even this kind of labeling runs the risk of continuing the conceptual habit of exceptionalism (often referred to as the "magic circle" issue, following Huizinga, 1971). Instead, I blur the distinction between these spaces and others where people act by more generally using the term domain. A domain is a semibounded arena for action where certain conventional expectations apply and certain resources may be available. Thus, the domain of legal practice includes the conventions and expectations that apply to people acting within it along with other aspects that similarly act both to constrain and enable, including the legal/procedural (that is, in the institutional sense); increasingly, the technical and technological (e.g., new avenues available for action including electronic filing, formatting, etc.); and others. Similarly, synthetic worlds are domains that present for their users an increasingly varied and complex set of affordances, including technical and architectural constraints, market forces, regularly applied national and other law, and social conventions. Domains are not set apart 
from everyday life - their separability from each other is practical, not fundamental. As Julian Dibbell (1998) put it most poignantly,

Socio-political reality is not that different, finally, from the virtual kind, and . . . a human being never inhabits a physical landscape without also inhabiting its ghostly abstract counterpart - the geography of language, law, and fantasy we overlay, collectively, on everything we look at. (p. 74)

Synthetic worlds are remarkable precisely because they both appear to generate phenomena that are sui generis, but at the same time they increasingly demonstrate how futile it is to see them as essentially set apart.

By the best available estimates, approximately 8 million people worldwide participate in them regularly (Woodcock, 2005). These domains, many of them games (that is, they have foundational and measurable game objectives), have become rich and immersive enough to be arenas where their participants pursue social ties, romance, professional interests, and commerce. Although it has been a challenge at times to establish to both the wider public and the academic community that these environments are anything more than playgrounds for the connected, the work of Edward Castronova $(2001,2003,2005)$ has made it undeniable that these worlds are generating "real" value.

His work and that of F. Gregory Lastowka and Daniel Hunter (2003) have shown not only that the economies within these worlds demonstrate, like all markets, the emergence of basic laws of supply and demand for desirable "virtual" goods (i.e., items, in-world currencies, and characters) but also that these goods are desirable enough that they appear for sale on auction sites (e.g., eBay or IGE) where they can be purchased with the U.S. dollar and other conventional national currencies. In fact, the stability of these economies (in the relatively short time frame available for us to observe) suggests that they are beginning to operate more like national economies themselves. The material economies of synthetic worlds are not only real then, they are large and growing larger; their existence as a site for the generation of market capital is becoming not just true but commonplace.

But this form of capital is not the only resource produced in synthetic worlds. Through their actions within them, people also cultivate new and existing social networks, as they do in other kinds of online communities (i.e., those that are forum based or even newer kinds of communities, e.g., myspace.com and facebook.com). To understand the significance of this, several researchers on online communities have turned to the concept of social capital, some following in particular the work of Robert Putnam (1995, 2000; Preece, 2002; Scott \& Johnson, 2005). But Putnam's account of social capital treats it not like market capital as a resource for individuals but instead as an index for diagnosing the collective civic health of a society, and this treatment inhibits further examination of how social capital and market capital might be interrelated. Whereas a shift in analysis to the level of collective goods may be a powerful move for the generation of public policy recommendations - where social capital for a society 
as a whole seeks to stand on a par with, for example, gross national product - it cannot simultaneously serve to illuminate the emergent social action of individuals and new groups that draw on obligations through their social networks as a resource just as they do their material resources. This more fruitful approach has been employed in the context of synthetic worlds by T. L. Taylor, Dmitri Williams, and others (Jakobsson \& Taylor, 2003; Steinkuehler \& Williams, 2005; Taylor, 2003; Taylor \& Kolko, 2003; Williams, in press), and this work provides a foundation for recognizing the ways in which social capital online not only is a resource for social action but also one that can be leveraged to cultivate market capital and vice versa.

As may already be obvious, by capital, I mean specifically a resource for action. In this sense, capital is always potential, something that is enacted only in the act of applying, invoking, using, or spending. Adding cultural capital to the conversation about the resources for action in synthetic worlds fills out the picture, allowing scholars to recognize the range of resources that actors have available to them. Work such as Castronova's and Taylor's not only establishes that these forms of value are created in synthetic worlds, it also begins to suggest that they may be converted one into the other and transferred across domains. It also prompts us to go further to identify other resources available to actors in synthetic worlds. Following Bourdieu (1986), I propose that we acknowledge a third form of capital as generated in synthetic worlds: cultural capital.

Cultural capital is the resource that participants develop and acquire in the form of competencies and credentials and that they also invest in valued cultural objects, or artifacts. ${ }^{1}$ All three of these terms are already casually present in discourse among and between synthetic world scholars, developers, and others interested in them (see e.g., the collaborative blog Terra Nova, http://terranova.blogs.com), but these discussions lack both specificity and a sustained effort to see how these forms are related one to the other. As these worlds become the site of more and more human activity, it is paramount that we articulate a more precise framework for understanding these forms as well as their use, transfer, and conversion. This will enable us both to advance the discussion of social action across all human domains and to create a common language for future empirical research.

In what follows, I outline and discuss these three forms of capital in their specific application for synthetic worlds. Two caveats are necessary before proceeding. First, this is a conceptually rather than empirically driven article, and as such, the examples I point to are illustrative rather than definitive or comprehensive. Readers with anything more than a passing interest in synthetic worlds and research about them will be familiar with the many fascinating but heretofore disparately treated examples of what social action in synthetic worlds makes possible. Other readers are directed to the scholarship already mentioned as a starting point. Second, and to avoid misunderstandings, I note that although I draw my illustrative examples primarily from Second Life, a synthetic world with which I am most familiar, I hold that this framework applies to all domains of human action, including all kinds of synthetic worlds, such as MMORPGs, that is, those with foundational game objectives in the form of an explicit advancement ladder (leveling). In short, this is because all of these persistent worlds generate, through the 
application of human effort over time and through the development of shared meanings, things (broadly defined) that are of value for their participants. ${ }^{2}$

Beyond establishing a common language for recognition and analysis of the effects of human action in synthetic worlds, I am pushing simultaneously against the distinction between them and the other places where people act and intend that the following framework, although outlining some of the specific concerns in applying this model to synthetic worlds, ultimately demonstrates that they are not fundamentally different after all. Instead, it is only a reorientation in our thinking about them and their possibilities that must take place. Of course, the synthetic nature of these domains also generates new empirical questions about how the effects of human action play out within them, particularly under conditions (deeply architected environments) where other people can exert control in extensive though not boundless ways (see Malaby, 2005). This means that particular worlds (Second Life, World of Warcraft) have particular and important differences in how forms of capital generate and circulate, but this framework is offered in part precisely to encourage mutually coherent work that explores these differences.

\section{The Forms of Capital in Synthetic Worlds}

Pierre Bourdieu's (1986) account of the "economy of practices" forms the basis for the following framework, and this account itself owes much to what Sherry Ortner (1984) called "practice theory," the broadly shared approach to understanding social reproduction and change pioneered by Michel de Certeau (1980/1984), Anthony Giddens (1984), Marshall Sahlins (1976), and Pierre Bourdieu (1972/1977). To set the stage for what follows then, I here too briefly summarize the main contours of this school of thought. The common thread is the emphasis on social action, that culturally shaped practices rather than transcendent structuralist accounts of any sort (i.e., historical materialism or Freudian psychoanalysis) together constitute human experience (in this respect they resemble the pragmatist philosophers, including William James, C. S. Peirce, John Dewey, and Oliver Wendell Holmes). The practice theorists sought to solve the problem of structure versus agency in accounting for social change by pointing to how macro-level patterns are the result of local-level actions, themselves shaped by the inculcated expectations of culture. This is a dynamic model that sees the complexity and contingency of everyday experience as the site for primarily the reproduction of social forms but always with the potential for both incremental and radical change.

For Bourdieu (1986), human practice over time accumulates in different forms, whether in the congealed labor of commodities, the lasting obligations of social networks, or the established cultural practices of taste. All of these forms of capital are then the product of human effort over time. To put it another way, human capital is the first resource for people, and with its application over time it generates material, social, and cultural capital. ${ }^{3}$ Importantly, this model is therefore in constant danger of the following misreading: that accumulated labor here is in some way equivalent 
to labor in its more familiar sense- that is, labor as (only) that which produces market capital. Such a misreading misses how the accumulation of human effort over time also includes acts of interpretation and exchange.

The construction of meaning by those who share experiences not only and obviously involves effort but also becomes over time somewhat durable, such that cultural competency, the command of one or more of such sets of meanings, can be passed on through learning. It is also portable in the sense that new situations are always unique, with the potential for the application of cultural competency in new ways. In fact, I believe that it is precisely the durability and open-endedness (contingency) of synthetic worlds that makes them fertile ground for these accumulated effects and that accounts for their rise as viable domains in the sense here described, although a full treatment of this argument is beyond this article's scope.

Thus, the economy of material exchange is but one dimension of human exchange more broadly, and these acts of exchange are, again, only constituted through human effort. Reciprocity, the moral relationship created through the mutual exchange of gifts and acts, is the means by which social capital is generated, and this is all but invisible to a strictly market-oriented gaze. Learning, the passing of competencies in language, etiquette, criticism, and all other culturally specific skills through the channels of family, profession, or other relationships, is another form of human exchange nearly invisible to the market. Finally, formal authorization - the conferral of degrees, licenses, and other credentials that objectify capacities of title or office-is the institutionalized form of exchange, primarily identified with educational systems, and although often involving market capital, these are also intractable to full marketization (despite the continued best efforts of neoliberal policies). This economy of practices is comprehensive in this sense. As Bourdieu (1986) stated,

The structure of the distribution of the different types and subtypes of capital at a given moment in time represents the immanent structure of the social world, i.e., the set of constraints, inscribed in the very reality of that world, which govern its functioning in a durable way, determining the chances of success for practices.... It is in fact impossible to account for the structure and functioning of the social world unless one reintroduces capital in all its forms and not solely in the one form recognized by economic theory. (p. 242)

For convenience, it is thus possible, at the risk of oversimplification, to identify each of the forms of capital with one or more things that are familiar to those in industrialized contexts. Thus, market capital includes commodities and currency, social capital includes connections, and cultural capital includes competencies, credentials, and artifacts.

For synthetic worlds, this model directs us to the shared practices, including meaning-making and different forms of exchange, that over time in synthetic worlds generate forms of capital, perhaps in these familiar forms but also possibly in new ones, and how they are parlayed across all domains of human action. It is vital to note at the outset however that although this model is meant to provide a comprehensive account of the economy of practices-that is, of the forms of human 
exchange-it is not a comprehensive account of human behavior generally. If it were taken as such, it would seem to reduce all human exchange as simply a means to an end. It is unavoidable that this model presents the actions of people within the economy of practices as oriented toward if not the maximization of market capital, at least the cultivation of their position on all fronts in the course of pursuing particular interests (whatever those may be). This necessarily draws attention away from human experience for its own sake, wherever it occurs, and from other dimensions of experience, such as suffering. This framework is therefore a powerful tool that can be used to illuminate certain processes not otherwise apprehensible, but it should not be taken as exclusive of other aspects of human experience. ${ }^{4}$

\section{Market Capital}

The most familiar form of capital, market capital tends to be both durable and transferable, existing in the form of goods and services (commodities) or currency. But the power of market capital lies in its liquidity, achieved most fully in the form of currency. Market capital, unlike other forms, enables exchanges that are immediate and isolated, demanding no corresponding moral exchange (reciprocity) or cultural exchange (learning and authorization), although these other dimensions are often present. In its ideal form then, market capital is a resource that can be drawn on in isolation from one's connections (one's social capital) or one's credentials and competencies, beyond the minimum cultural competencies required by the market itself.

Commodities. Synthetic worlds have surprised many with the degree to which they generate tradable goods that can now be found easily through online markets (eBay, IGE, as noted earlier). Although the lack of tangibility to these goods makes some of those unfamiliar with synthetic worlds initially hesitant to accord them equal status with offline goods, it should take only a moment's consideration to render such reactions untenable as a basis for analytical distinctions. The purchase of goods that we durably own but that are intangible applies equally well to such items as software, telecom accounts, ring tones, and other elements of digital life that people rely on around the world. Lastowka and Hunter (2003), writing from a legal point of view, demonstrated that both normatively and descriptively these goods must be considered property, and this signals a larger trend where the status of information as a commodity is becoming undeniable. The extent to which this commodification process relies increasingly on a technological infrastructure that operates according to implicit and increasingly autonomous algorithmic processes is an important site for further inquiry. Synthetic worlds, by their nature both architected and open-ended enough for the emergence of robust social phenomena, are a perfect starting place for this research.

Initial skepticism may also be colored by a suspicion that these virtual commodities are, like the worlds themselves, somehow not serious or worthwhile. Whether these goods are frivolous however is a normative question, and in any case it is one that presupposes the very kind of distinction - that these are worlds without consequences, 
as opposed to the "real world" with its consequences - that the reality of synthetic world economies should help us overcome.

In any case, commodities are the most obvious case of the exchange of value across worlds as they are widely available for purchase through simple credit card transactions. Buyers thus convert their market capital (in the form of currency, or credit) into market capital in the form of commodities, virtual goods, but they do it not simply within the world's economy but across the world's economy and the national economy of their currency. (This is analogous to the purchase over the Internet of goods from another country.)

But the most important feature of synthetic world commodities is the way the costs of producing or distributing them are transformed, and this is an important avenue for future research. Many synthetic worlds, particularly those that follow the MMORPG model, have imposed scarcity, such that acquiring, making, or developing things of value demands significant amounts of time and also such that most objects of value cannot easily be duplicated. As a result, the values for these commodities can bear a strong relationship to the amount of time required to make them. Of course, these efforts to control scarcity on the part of the worlds' makers are not immutable-players with the right access (perhaps by drawing on social capital) or abilities (cultural capital) can hack or exploit under certain circumstances; this is just one more way that these domains exhibit their complexity - they cannot be perfectly governed.

Also at play here is the use value of the item, that is, what it allows you to do, whether as a marker of status, an element of in-game combat, or otherwise. This value, the product of the item's supply and demand, nonetheless can be exploited by those who acquire or make them for sale by the application of cultural capital in the form of competence or credentials necessary or advantageous (in terms of minimizing time) to acquire the item or by the application of social capital (connections) to locate the item and so forth. That difference- that is, how much easier it is for someone to acquire or make an item more efficiently than a prospective buyer-is what the seller depends on to make a profit.

So in the generation of these commodities we already see multiple kinds of resources in play as players in MMORPGs leverage them to generate commodities that can be exchanged for currency. It is also worth noting that the distribution costs are in any case transformed as the virtual nature of the commodities makes their transfer relatively easy, although this importantly depends as well on the architecture of the synthetic world itself: Can items for example be sent via asynchronous communication (e.g., e-mail) from one account to another? Must this be done within the world? Even more interesting is to consider the limits of these objects' use value. Can we imagine that some of them could be "used" outside of their original domains? What are the consequences of someone posting screenshots or other "proof" of ownership of an item to personal blogs and photo-sharing sites? To what extent are items constrained by the "story" of the world from which they originate?

Second Life and others like it (ActiveWorlds, There) are different on this point, with important consequences for the configuration of these forms of capital. In these 
worlds the (re)production and distribution costs of creating items are both drastically reduced. Second Life in particular is built on the premise that users make their own content and that they furthermore own the intellectual property rights to whatever they make. Objects made in Second Life can be set by their original maker to allow (or disallow) further transfers, copying, or modification (Ondrejka, 2004). Thus, in Second Life not only is it extraordinarily inexpensive to distribute items, but also their duplication costs are near zero as well. As a result, the investment of time and effort involved designing and (initially) making in-world commodities has a disproportionate weight for these synthetic world commodities.

Research questions for this kind of synthetic world economy are multiple. With so little "overhead" for commodities, how is their market value established? Do these commodities get their value at least in part because of their analogous relationship to offline commodities; that is to say, is the value of a Second Life house somehow related to how we value offline houses? It is here that we must confront how the value of commodities can rely as much on a set of cultural meanings in addition to the factors heretofore described. A common example is that of the baseball card; its value accumulates relative to the cultural importance placed on such objects, which elevates some materially nearly worthless items to an exalted status, as "memorabilia" or the like. As outlined in the following, this is a particular form of cultural capital, its objectified state, but I foreshadow that discussion here because cultural capital is conventionally parlayed into market capital through events such as assessments, appraisals, and the like, which themselves depend on a combination of scarcity and meaning. We might then ask: If the cultural capital of meaningful objects is generated in synthetic worlds, how are these forms of nostalgic value supported or undermined by the nature of virtual items as potentially replicable code themselves?

There is a further wrinkle to understanding commodities in synthetic worlds: How are services to be understood? Are they a form of market capital? Services are highly commodified, but they are not durable and transferable in the ways that most commodities or currencies are. What is more, they appear to be a direct application of cultural capital (expertise) rather than the accumulation of human capital that we see in goods, virtual or otherwise. Nonetheless, services are a form of market capital because what is purchased is the labor and expertise of one or more others as delimited by time. ${ }^{5}$ Purveyors of services sell their time and hence make a direct parlay of their embodied cultural capital, acquired in human effort over time, into market capital that is the application of cultural capital in time. The distinguishing feature of market capital transactions still remains, the service transaction is minimally possible without any necessary elements of moral obligation (reciprocity) or learning and authorization.

There are a number of services sold in synthetic worlds, such as notary services (see following), design consultations, writing services, and (in World of Warcraft, WoW hereafter) enchanting and lock picking. Here, as in offline experience, the conversion of cultural capital in the form of both competencies and credentials into market capital is accomplished by applying those competencies through time, and that application of 
competencies in the service is the exchangeable commodity, the market capital. A number of important questions remain: How are emerging or existing means to display competence and credentials involved in service providers' efforts in the marketplace? Do services, as so closely tied to competence and credentials, rely also more heavily on social capital; that is, are social networks as opposed to advertising and other forms particularly good paths to potential customers? In all of these dimensions, how does the architecture of synthetic worlds specifically shape these practices?

Currency. Currency is market capital in its most liquid form: highly transformable, frequently anonymous, and productive of immediate exchanges that most clearly suggest no moral relationship (Parry \& Bloch, 1989). Unlike commodities, which have a use value, currency has value only in its exchange for other currencies, commodities, or when parlayed into other forms. Many theorists have noted that as a phenomenon money is ultimately and peculiarly reliant on a shared sense of trust, and many of the ingredients of this trust are deeply practical. ${ }^{6}$ Common practical knowledge and use of currency provides one part of the foundation required for any money to be "real" and to represent and store "real" value (Dominguez, 1990). Unlike commodities then, currency has long been embedded in the mundane practices of person-to-person transactions, involving verification both of the currency itself and of the transaction (ensuring correct amounts, change, and proper application of things like taxes and fees). In the absence of many of these features of cash transactions in synthetic worlds, how is collective trust in currency established?

Actually, this transition in the foundations of trust in currency from the mundane to the virtual is already under way for conventional currencies. The establishment of the euro is a particularly apt case that illuminates the position of virtual currencies. The euro was a fascinating and perhaps unprecendented instance where the introduction of a virtual currency not only preceded its physical rollout, it was deemed a necessary test of the currency's viability (Malaby, 2003). This reversal reflected an important landmark in what is in fact a long transformation in the concept of trustable currency, away from specie and toward an abstract representation of value. For much of the past two centuries, this transformation has hinged on the effectiveness of verifying the physical currency itself and in fact on training citizens to be competent (that is, to have the cultural capital, see following) to verify their currency in the course of face-to-face exchange. With the euro's rollout, the first test of verification of the currency rested not on mundane, unmediated verification by everyday users but instead on the establishment of its value online, in currency markets, where it was available 2 years before it ever saw the streets.

What does this mean for synthetic worlds? It demonstrates that the generation of value for currencies is already resting increasingly not on the physical verification of notes and coins but on the collective trust in networked financial institutions, including currency markets, banks, and transaction verification services (like VeriSign and PayPal), and this is built in turn on the increasing familiarity on the part of a small, wealthy segment of the global population with the practices of virtual trade. In short, 
it demonstrates in a different way why we should not be surprised to see virtual world currencies act like more familiar currencies; after all, the euro itself was virtually real first, and this signals that the very foundations of the peculiar phenomenon of money are shifting further toward the institutional and away from the phenomenological.

For synthetic worlds, this raises the following question: What kinds of institutions underwrite virtual currency? Is it the company that makes the world itself, existing banks and other financial institutions, new third-party vendors, currency markets, or some combination? How is the relationship of trust necessary for the legitimacy of a currency established among these institutions and between them and the users, and therefore how might we recognize practices of reciprocity in this process? Just as important, how does the architecture of the Internet itself and of particular domains shape users' practices and expectations so as to generate new paths toward legitimacy for lending institutions?

One answer may be found in the establishment of Stagecoach Island, by Wells Fargo bank, on a private island within Second Life in late 2005 wherein residents could participate in a private economy. According to news.com: ${ }^{7}$

Visitors there can skydive, fly hovercrafts, dance and shop. But woven into the experience, to which Wells Fargo has been inviting groups of people in San Diego and Austin, Texas, is a series of financial messages intended to help them learn something about money management.

Stagecoach Island takes place on several private islands inside Linden Lab's virtual world, "Second Life." But while "Second Life" is open to the public, the Wells Fargo islands are accessible only by those who have received invitations from the bank and, thus, is branded entirely as a Wells Fargo environment. Regular "Second Life" members cannot access Stagecoach Island. . . . Stagecoach Island players are given \$30 in imaginary money with which to buy clothes, pay for rides and the like. The idea, though, is to teach the players to save money-they earn 10 percent per day on "deposits"- and to learn new things about money management through a series of quizzes that, when completed, reward players with $\$ 5$ of new funds.

By making access to the island and an allowance in its virtual currency available for free, or rather in exchange for contact information, to select young adults, Wells Fargo aspired to leverage its cultural capital as a credentialed financial institution with its social capital in its connections to select groups to generate both market capital in the form of new accounts and the cultural capital of the credential of widely acknowledged competence in online finance.

\section{Social Capital}

Social capital is a resource that depends on the special qualities of reciprocity, as first outlined by Marcel Mauss (1923-1924/1967). Unlike immediate and equivalent exchanges, such as those of the market, reciprocal exchanges (in the form of objects, favors, expressions of concern, etc.) imply a moral relationship, where the account is "never settled" between individuals or groups. Central to this phenomenon is time, 
but in contrast to the commodification via delimited time in the service industry, here time is specifically not delimited: Any given exchange continues a relationship into the future, leaving open the possibility of the nature and quality of the next transaction. Over time, social capital is the resource constituted by these relationships, one that can be drawn on for advice, support, or other resources. As such, social capital must be cultivated, maintained in a way that market capital does not require.

There is a danger however in the application of social capital in research, and it bears mentioning here. It is always possible to mistake the network itself for the resource, for social capital. In fact, social capital is not the abstract link of familiarity between two people (then generalized out to include a group), it is always and only the state of their moral relationship of mutual obligation. A network then is only a residual effect of a set of ties, any one of which may be in a different state particular to the relationship on the ground.

Connections. In synthetic worlds, social capital is a resource that has garnered increasing attention, primarily with respect to the generation of new social relationships within synthetic worlds and also with respect to how social ties can bridge within and between synthetic worlds and other domains of social action. It is perhaps not surprising then that we are drawn first to identify the familiar social groups within worlds (i.e., guilds) or the ones outside of them (i.e., kin networks or peer networks), all of which recreate or draw on conventional forms of social organization. But we thereby pay less attention to the practices of reciprocity that create and sustain these networks. This is unfortunate because a research focus on the practices of reciprocity in synthetic worlds would allow us to see where new forms of social networks get created, even if they are never realized into conventional social forms. I am thinking in particular here of guild structure in conventional MMORPGs, where a form of social organization is architected into the code of the world itself, and how focusing on this as the social formation par excellence in WoW might blind us to other kinds of social networks (e.g., those associated with WoW's auction houses).

This should also prompt us to inquire about the architecture of synthetic worlds to see what kinds of tools and constraints on social interaction are available for users in their generation of practices of reciprocity. Notecards in Second Life for example have come to be a particularly flexible tool for a range of reciprocal actions, as for a time was its rating system, with which new acquaintances were expected to reciprocally rate each other positively.

The leveraging of social capital into other forms of capital is in any event particularly easy to recognize, whether in how guild members in MMORPGs share material (items, currency) or cultural (training, advice) resources or in the formation of interest groups within Second Life that enable networking for commercial opportunities. But the parlay of social capital into other forms is also possible across domains, with a prominent example being the novelist Cory Doctorow's launch of his newest novel in virtual form within Second Life. Doctorow, with the credentials (a published author) and competence (the ability to write this novel and others and to present about 
his work publicly), made use of his connections with the Second Life community (and one if its primary journalists, Wagner James $\mathrm{Au}$, in particular) to create an event where virtual copies of his book (designed by residents in a competition) were available and at which he was available to talk about the work and to sign the books (virtually). ${ }^{8}$ The Second Life copies of the book were free, so a direct parlay of social and cultural capital into market capital for Doctorow was not the effect, but this does not mean that the event had no consequences in terms of market capital for Doctorow, who argues that such distribution in fact increases his material gain from writing. In any case, the parlay was one that is all the more interesting because market capital was not at its forefront. As in many such events, on- and offline, the conversion of social capital into cultural capital (in the form of status) is the central parlay. ${ }^{9}$

\section{Cultural Capital}

Cultural capital is the realization of what a given cultural group finds to be meaningful or important in bodies, objects, and offices. It includes those competencies and credentials that individuals or groups acquire over time within a particular historical context and also the objects that become valuable through their association with such meaning. It has three forms: embodied, objectified, and institutionalized (Bourdieu, 1986). Cultural capital is distinctive for its specificity to a context of meaning and practice, such as existing ones associated with nation, class, region, or sources of social separation, and thus its acquisition is not amenable to immediate and isolated transactions. Instead, cultural capital is acquired through the culturally embedded practices of learning, in the informal sense, and authorization, in the official sense. Such exchange generates a feeling of belonging, of identification with a cultural group. The exception is cultural capital in the objectified form, here termed artifacts, where the purchase of such goods does not entail the cultural competence necessary to consume, that is, "appreciate" them.

Competencies (embodied). The competencies embodied in individuals as a result of their learning form a basic resource for action. It is the application of this cultural capital in action that enables an individual to engage the world and to interact with others in it at all, beginning with the basic application of language and gesture but encompassing all other means by which individuals come to be able to act meaningfully. A very small set of examples includes making small talk, literacy, hitting a major league curveball, navigating social service bureaucracies, tracking and hunting a deer, tracking and clicking on a target in a networked computer game, typing witty comments quickly in a synchronous chat-based environment, and demonstrating unflappability in the face of unexpected gambling losses.

These competencies are acquired through learning, often in childhood, a practice that involves long-term tutelage under the guidance of either competent others, such as parents, teachers, mentors, or peers, or the objectified cultural knowledge found in objects such as books, tools, built environments, and technology. ${ }^{10}$ Cultural 
competencies are powerful markers of background and are more specifically associated with cultural distinctions such as class, gender, ethnicity, profession, religion, age group, and many more. Jerome Karabel (2005) recently documented how over the course of the 20th century, Harvard, Princeton, and Yale developed admissions policies that gathered information to evaluate applicants in terms of a broader array of cultural capital than simply scholastic ability. This allowed them, for example, to slow the rise of successful Jewish entrants over the first half of the 20th century. By expanding their forms of information gathering and evaluation into such things as athletic team membership they sought to measure "character," a form of cultural capital that could be relied on as a predictor of future wealth because it excluded those not already enculturated to the relatively ethnically homogenous upper class.

In synthetic worlds, we see a scene much more in flux as the cultural competencies within it are very much in the process of becoming, and this perhaps means that the economy of practices does not currently, as in Karabel's (2005) cases, simply reproduce entrenched socioeconomic differences. Where in synthetic worlds then are existing competencies finding new purchase, and where are new competencies generated? Edward Castronova (2005) sought to account for this capital in synthetic worlds in his recent work by separating these competencies into human capital, which pertains to the in-the-flesh user, and avatar capital, those competencies held by the avatar in a synthetic world. The sticking point here is that the competencies Castronova described are in all cases only held, ultimately, by the in-the-flesh actor (or group of such actors), whether in a synthetic world or not. The competencies are inescapably embodied. The fact that some of these competencies may require a tool or technologically mediated environment (with the avatar and everything else this implies) does not change this fact, and thus to separate the physical from the avatar is to reintroduce a gap between online and offline that does not in fact exist. More familiar competencies-piloting an airplane, rowing a canoe, handling customer service telephone calls, pedaling a bicycle, or even writing itself-also require the proper circumstance to be employed at all, including the requisite technologies and forms of mediation. That said, what Castronova hit on is the extent to which an avatar may not only represent a user in a world (to others and to the user himself or herself), it can also become an object of cultural capital, an object that uniquely bears a history, with specific experiences, objects, and credentials. Thus, there are forms of value that accumulate within the avatar itself, as an artifact, that cannot be transferred out of it. ${ }^{11}$

There is more to be explored here, and a full rehearsal of theories of the avatar is beyond this article's scope in any case. I will only note that the avatar bears for anthropologists a striking similarity to roles prominent in ritual, such as the Tsimshian potlatch of the Pacific Northwest. The most recent work on the Tsimshian (Roth, 2002) emphasizes the potlatch not as an occasion for the spectacular destruction of excess wealth but rather as an event about the inheritance of "names," the ritual offices held by lineages ("houses") that contain an extensive set of obligations. They are passed down only under the proper conditions, involving extensive material outlay, and this effort is 
itself risk filled, subject to all the contingencies of any large-scale and involved social drama. Of course, the same kind of parlay between different forms of capital is happening here as well, but the key point for a consideration of the avatar is that these names have the same dual characteristics, at times potentially objectified, when listed as part of the lineage's property, and at other times directly and inextricably associated with the unique circumstance and capacities of the persons holding them at any given time.

As Roth (2002) wrote, "The dual nature of names as objects of wealth and as personages ... corresponds to the dual nature of a structure of names as both a store of wealth and a social structure of individuals" (pp. 132-133). Whereas avatars are currently far more strongly associated with individuals and therefore do not (yet) index a social structure within synthetic worlds in anything but an embryonic way (through their association with guilds, most obviously), the dual principle Roth noted applies nonetheless: Avatars have characteristics of objects or property and characteristics of personas. We may yet see the day when certain avatars (e.g., guild leaders) are transferred with great ceremony to other users as a matter of course within synthetic worlds as their original owners pass them along due to death or other life changes.

If we think of competencies developed within and across synthetic worlds then as essentially not different from those individually and collectively developed in other domains, we begin to see more easily how the application of such competencies can itself transcend one domain for the other, and this is most obviously seen in the case of the military's use of networked synthetic world technology, where the embodied abilities of interface manipulation, team communication, and corporeal coordination are effectively cultivated within gaming environments. All of this means that there is currently an important opportunity for researchers to explore how competencies from synthetic worlds are beginning to be applied beyond them, but it also suggests that institutionalized forms of such capital may currently be arising as well.

Credentials (institutionalized). Institutionalized cultural capital appears when capacities are formalized into offices and licenses, when an institution with a purview over a certain arena gives its imprimatur to an individual or group as authorized to carry out certain kinds of activities. Thus, it is capacity removed from the body of an individual and reified as a credential, and a credentialed individual may or may not have all of the competencies thereby implied. The credential nonetheless acts as a resource for action in any case as a credentialed actor can carry out acts formally allowed by the institution, many of which may in fact be disallowed otherwise. Marrying a couple, firing someone, and speaking or signing a contract on behalf of an institution are all instances of the application of institutionalized cultural capital. Bourdieu (1986), speaking specifically of institutionalized cultural capital in the form of academic credentials, elaborated,

With the academic qualification, a certificate of cultural competence which confers on its holder a conventional, constant, legally guaranteed value with respect to culture, 
social alchemy produces a form of cultural capital which has a relative autonomy vis-à-vis its bearer and even vis-à-vis the cultural capital he effectively possesses at a given moment in time. (p. 248)

So where do we find credentials in synthetic worlds? Future research may inquire into the appearance of education in synthetic worlds, both on the part of existing education institutions (e.g., the growing community of academics from conventional universities making use of Second Life in their classes) and of new ones (new groups of educators that emerge within and across synthetic worlds).

But credentials appear in noneducational contexts as well, as the recent case of Zarf Vantongerloo in Second Life illustrates. Zarf set up shop in Second Life as a notary public, verifying that documents submitted to him are signed by the parties involved at a specific time and retaining a verifiably unchanged version of the document at an offsite (out of Second Life) server. ${ }^{12}$ How are his credentials as a notary (he is not one beyond Second Life) established? In his interview with Zarf, James Wagner Au asked,

"So really ... the only possible flaw in all this is whether everyone trusts you and your code, right?"

“. . . which is true of any notary," Zarf replies. "In real life, the state makes you take a test and you [do] some reporting requirements-but you have to trust that the notary down the street isn't faking your signatures on things. So yes, you have to trust me to not create fake notarizations." He says his code is open source and verifiable in common software packages like OpenSSL, so "the only part of my code you need to trust is how I ensure that my communications are tamper proof."

Here, Zarf points to open source verification software to establish his credentials, an innovative way to appeal to credibility in waters that are currently uncharted by any state institution (as Zarf notes elsewhere, his research suggested that in fact virtual notaries might be disallowed by much existing legislation). As academics interested in synthetic worlds have suggested (Crawford, 2005), following a legal realist approach, there are good grounds for believing that acts such as those by Zarf may generate legitimacy for themselves from the ground up once they are employed and relied on by sufficient numbers of actors. Enlightened public policy might allow new formal laws (or interpretations of existing laws) to follow a then-established cultural practice.

Artifacts (objectified). Artifacts are objects that draw a significant amount of their value from their status as repositories of cultural capital. Invested within them are meanings from a given context, and examples include antiques, art, baseball cards, and books. I have noted some of the features of artifacts earlier in their connection with the market economy, but here is where we can return to the example with which I began this article: the trading card for Kermitt Quirk's Tringo.

The card juxtaposes key components of an effort to establish Second Life as an environment with real consequences, material and otherwise, and to do so it points to 
the various forms of value that actions in Second Life generate. I indicate just a few of these here. First, note that the first item in the trading card's list of Tringo's attributes (analogous to facts about an athlete) is "Creator," which answers one question about the card's purported subject, Tringo. But every item thereafter refers not to Tringo but instead to Kermitt Quirk, who has taken over the focus of the information. We then learn, in quick succession, that he has been a resident since 9/4/2004 (seniority is one of the first terms on which social difference is constructed), that his First Life occupation is systems analyst/programmer, and that his Second Life occupation is game developer. This juxtaposition places an occupation in Second Life ontologically on a par with one's occupation in the conventional sense.

We learn the name of his business and when it will appear, but it is not a "Second Life Business"- the business as an entity transcends whatever boundary we might expect between First and Second Lives. We are given the location of one of his stores, but the (for the uninitiated) cryptic coordinates are the only indication that this is within Second Life. Lastly, we learn about his net worth, in L\$ and US\$, again with an element, "L\$," tantalizingly undefined. We then hear of the "business milestone" of Quirk selling distribution rights to Donnerwood Media for "five figures" and hear Quirk himself comment on this, first in brief and then at length. He points to how the speed of events surprised him even though he always intended to sell Tringo and to how he relied on word of mouth to grow his business.

The Tringo trading card, in teaching us about Kermitt Quirk, makes a set of claims about how we are to understand the relationships between a product, money, credentials, skills, and networks. Quirk has credentials outside of Second Life (systems analyst/programmer) that can be applied within Second Life. He now has a credential in Second Life, authorized by the signing of the contract with Donnerwood Media, that could be applied beyond it. He has assets in the form of a business and in-world net worth, the latter of which is readily describable in and, it suggests, convertible into US\$. Quirk also has a network of people who know about, enjoy, and recommend his product such that he as yet does not need to advertise. Beyond this, he, or the game, has a trading card! Again, the card itself aspires to add to the economy of practices by existing in a form distributed by Linden Lab and potentially to be valued. More fundamentally however, Second Life itself stands in this picture as an environment where all of this can be done, as a place where one can viably leverage skill into connections into credentials into a product into money and all combinations thereof.

\section{New Business}

How successfully Second Life actually stands as a site for the generation of parlays between forms of capital within and across domains of human action as the trading card describes is a question for further research for which the framework outlined earlier is intended. With it, we can now begin to engage seriously the relationship 
within and between the various domains of human activity, broadly speaking. The boundaries that only appeared to separate the real and the virtual are fading fast, from both sides, and it is the social actors on the ground who are making use, in every new moment, with every new challenge, of the increased scope that these new domains afford. Without the proper tools to describe their efforts, academic understanding of the digital society will lag irredeemably behind.

By thinking in terms of the forms of capital within and beyond synthetic worlds, researchers will be able to chart how human actors move within and among different domains of all kinds, converting different forms of capital into one another. Crucial to this effort will be empirically grounded accounts that encompass not only the new opportunities but also the new constraints, charting the costs, broadly speaking, of interdomain parlays and how they are shaped by the architectural choices of the makers of synthetic worlds. If researchers can begin to articulate this economy of practices, we will be well placed to probe further not just into the implications of synthetic worlds but into the nature of digital society.

\section{Notes}

1. Edward Castronova (2005) began to explore similar ground in his book, Synthetic Worlds, although in different language (see e.g., pp. 110-114). I point out important differences between our arguments in what follows.

2. There is a further dimension to the argument that is beyond the scope of this article, but I mention it here. A position that massively multiplayer online role-playing games (MMORPGs; as opposed to "social" virtual worlds) are not covered by the framework I outline here is a form of untenable exceptionalism. Any account of MMORPGs that exclusively appeals to their status as games to explain how or why they generate these forms of capital implicitly re-creates a hard distinction between gaming and not gaming as distinct modes of human experience, and this itself relies on a modernist association where games=play=lack of consequences/productivity/seriousness (see Malaby, 2004).

3. For Edward Castronova (2005) by contrast, human capital is the intangible education and experience that enhance earning power. Because this capital is highly culture specific - its competencies are linked directly to a particular historical-cultural situation-it falls in my treatment under the more specific heading of cultural capital. Human capital is reserved for the more fundamental resource of human effort over time itself.

4. Note that this model may not in this form confront many of the most pressing questions about the transformation of individual subjectivity in the context of networked technology. How is one person's position vis-à-vis material, social, and cultural capital transformed if that person's identity is no longer simply human but in fact posthuman, with identity increasingly mediated through information technology that emphasizes the reproduction of pattern over presence (Hayles, 1999)? It may be that we must begin to incorporate intelligent machines themselves into this framework, accounting for how their collection, manipulation, and transfer of information also influence material, social, and cultural capital.

5. Although technology has important consequences for the manipulation of time for its users, what matters for time in the commodification of human capital is the human time required.

6. See Crump (1981, p. 8), Simmel (1900/1978, p. 153), Cohen (1998, p. 11-12), Leyshon and Thrift (1997, p. 30 and passim), among others. .html.

7. http://news.com.com/Wells+Fargo+launches+game+inside+Second+Life/2100-1043_3-5868030

8. One account of the event can be found at http://secondlife.blogs.com/nwn/2005/07/day_of_the_ doct.htm. 
9. Reciprocity as the basis for the establishment of social relations that could be drawn on to acquire status is classically represented in the "big man" system at one time prevalent in Melanesia. See Sahlins (1963).

10. For an exploration of this phenomenon for computer games, see Gee (2003).

11. I wish to thank James Paul Gee in particular for this insight.

12. See http://secondlife.blogs.com/nwn/2005/10/laying_down_the.html.

\section{References}

Bourdieu, P. (1977). Outline of a theory of practice (R. Nice, Trans.). Cambridge, UK: Cambridge University Press. (Original work published 1972)

Bourdieu, P. (1986). The forms of capital. In J. Richardson (Ed.), Handbook of theory and research in the sociology of education (pp. 241-258). Westport, CT: Greenwood.

Castronova, E. (2001). Virtual worlds: A first-hand account of market and society on the cyberian frontier (CESifo Working Paper No. 618). Retrieved January 5, 2006, from http://papers.ssrn.com/ abstract $=294828$

Castronova, E. (2003). On virtual economies. Game Studies, 3(2). Retrieved January 5, 2006, from http://www.gamestudies.org/0302/castronova

Castronova, E. (2005). Synthetic worlds: The business and culture of online games. Chicago: University of Chicago Press.

Certeau, M. de. (1984). The practice of everyday life (S. Rendall, Trans.). Berkeley: University of California Press. (Original work published 1980)

Cohen, B. J. (1998). The geography of money. Ithaca, NY: Cornell University Press.

Crawford, S. (2005). Shortness of vision: Regulatory ambition in the digital age. Retrieved January 5, 2006, from http://papers.ssrn.com/sol3/papers.cfm?abstract_id=681409

Crump, T. (1981). The phenomenon of money. Boston: Routledge Kegan Paul.

Dibbell, J. (1998). My tiny life: Crime and passion in a virtual world. New York: Holt.

Dominguez, V. (1990). Representing value and the value of representation: A different look at money. Cultural Anthropology, 5, 16-44.

Gee, J. P. (2003). What video games have to teach us about learning and literacy. New York: Palgrave MacMillan.

Giddens, A. (1984). The constitution of society: Outline of the theory of structuration. Cambridge, UK: Polity.

Hayles, N. K. (1999). How we became posthuman: Virtual bodies in cybernetics, literature and informatics. Chicago: University of Chicago Press.

Huizinga, J. (1971). Homo ludens. Boston: Beacon.

Jakobsson, M., \& Taylor, T. L. (2003). The Sopranos meets EverQuest: Socialization processes in massively multiplayer games. Retrieved January 25, 2006, from http://www.fineartforum.org/Backissues/ Vol_17/faf_v17_n08/reviews/jakobsson.html

Karabel, J. (2005). The chosen: The hidden history of admission and exclusion at Harvard, Yale, and Princeton. Boston: Houghton Mifflin.

Lastowka, F. G., \& Hunter, D. (2003). The laws of the virtual worlds. California Law Review. Retrieved January 5, 2006, from http://ssrn.com/abstract $=402860$

Leyshon, A., \& Thrift, N. (1997). Money/space: Geographies of monetary transformation. New York: Routledge.

Malaby, T. (2003). The currency of proof: Euro competence and the refiguring of value in Greece. Social Analysis, 47, 42-52.

Malaby, T. (2004, September). Ethical code: Engagements and evasions in the design of virtual worlds. Paper presented at the Association of Internet Researchers annual conference (AoIR 5.0), University of Sussex, UK. 
Malaby, T. (2005, April). Coding control: Ethics and contingency in the production of online worlds. Paper presented at Command Lines: The Emergence of Governance in Global Cyberspace, University of Wisconsin-Milwaukee.

Mauss, M. (1967). The gift: Forms and functions of exchange in archaic societies (I. Cunnison, Trans.). New York: Norton. (Original work published 1923-1924)

Ondrejka, C. (2004). Aviators, moguls, fashionistas and barons: Economics and ownership in Second Life. Retrieved January 5, 2006, from http://papers.ssrn.com/sol3/papers.cfm?abstract_id=614663

Ortner, S. B. (1984). Theory in anthropology since the sixties. Comparative Studies in Society and History, 26, 126-166.

Parry, J. P., \& Bloch, M. (Eds.). (1989). Money and the morality of exchange. Cambridge, UK: Cambridge University Press.

Preece, J. (2002). Supporting community and building social capital. Communications of the ACM, 45(4), 37-39.

Putnam, R. D. (1995). Bowling alone: America's declining social capital. Journal of Democracy, 6, 65-78.

Putnam, R. D. (2000). Bowling alone: The collapse and revival of American community. New York: Simon \& Schuster.

Roth, C. F. (2002). Goods, names, and selves: Rethinking the Tsimshian potlatch. American Ethnologist, $29,123-150$.

Sahlins, M. (1963). Poor man, rich man, big-man, chief: Political types in Melanesia and Polynesia. Comparative Studies in Society and History, 5, 285-303.

Sahlins, M. (1976). Culture and practical reason. Chicago: University of Chicago Press.

Scott, J. K., \& Johnson, T. G. (2005). Bowling alone but online together: Social capital in e-communities [Electronic version]. Community Development: Journal of the Community Development Society, 36(1), 1-18.

Simmel, G. (1978). The philosophy of money (T. Bottomore \& D. Frisby, Trans.). Boston: Routledge Kegan Paul. (Original work published 1900)

Steinkuehler, C. A., \& Williams, D. (2005, June). Where everybody knows your (screen) name: Online games as "third places." Paper presented at DiGRA 2005: Worlds in Play, Annual Conference of the Digital Games Research Association, Vancouver, Canada.

Taylor, T. L. (2003). Multiple pleasures: Women and online gaming. Convergence, 9(1), 21-46.

Taylor, T. L., \& Kolko, B. E. (2003). Boundary spaces: Majestic and the uncertain status of knowledge, community, and self in a digital age. Information, Communication, \& Society, 6, 497-522.

Williams, D. (in press). Groups and goblins: The social and civil impact of an online game. Journal of Broadcasting and Electronic Media.

Woodcock, B. (2005). An analysis of MMOG subscription growth, version 18.0. Retrieved December 14, 2005, from http://www.mmogchart.com.

Thomas Malaby is associate professor in the Department of Anthropology at the University of Wisconsin-Milwaukee and is cocoordinator of the Modern Studies Program. He has published articles and essays on practice theory, risk, mortality, and history, and his book, Gambling Life: Dealing in Contingency in a Greek City (University of Illinois Press), explores human attitudes toward risk through an examination of the practice of gambling in Crete. His principal research interest is in the relationships among modernity, unpredictability, and technology, particularly as they are realized through games and gamelike processes. He is in the process of coediting a book, Command Lines, which explores the emergence of governance (in its various forms) online. His current research project, supported by the National Science Foundation, examines how ethics are encoded and emergent in the production of complex online synthetic worlds through ethnographic research at Linden Lab, makers of Second Life. 